
Branko Marušič znanstveni svetnik ZRC SAZU v pokoju Pot na Drage 4, SI-5250 Solkan, Slovenija branko.marusic@guest.arnes.si

\title{
Hrvaški korespondenti dr. Henrika Tume
}

Stručni rad | Professional paper

UDK 34 Tuma, H.(044)

Primljeno: 5. XI. 2010.

\section{Izvleček}

Prispevek opozarja na korespondiranje slovenskega javnega delavca dr. Henrika Tume s posamezniki in ustanovami s področja Hrvatske. Večji del gradiva še ni bil objavljen. Tumovo zapuščino hrani Raziskovalna postaja ZRC SAZU v Novi Gorici.

\section{Sintesi}

L'articolo pone l'accento sulla corrispondenza scritta dell'impiegato pubblico sloveno, il dottor Henrik Tuma, con persone ed istituzioni provenienti dal territorio della Croazia. La maggior parte del materiale non è ancora stato pubblicato. Il lascito di Tuma è custodito presso la Raziskovalna postaja ZRC SAZU di Nova Gorica.

Ključne besede: Henrik Tuma, Hrvatska, korespondenca, planinstvo Parole chiave: Henrik Tuma, Croazia, corrispondenza, alpinismo 
Odvetnik dr. Henrik Tuma (1858-1935), slovenski politik, publicist, domoznanski pisec in alpinist je v času svoje več kot polstoletne navzočnosti v javnem življenju navezal osebne in korespondenčne stike tudi z nekaterimi osebnostmi iz hrvaške javnosti pa tudi z nekaterimi hrvaškimi ustanovami in društvi. ${ }^{1}$ Tuma, po rodu Ljubljančan, je skoraj pol stoletja preživel na slovenskem Primorskem (Postojna, Trst, Tolmin, Gorica), zlasti med bivanjem v Trstu se je družil s predstavniki istrskih Hrvatov. Del celotne Tumove korespondenčne zapuščine je bil že objavljen, ${ }^{2}$ del pa še čaka na objavo. ${ }^{3}$ Ta prispevek našteva Tumove hrvaške dopisovalce in na kratko označi vsebino teh korespondenčnih stikov. Korespondenti so prikazani v abecednem redu. Kot publicist, zlasti kot marksistični teoretik, je obravnaval tudi hrvaško družbeno problematiko v sklopu svojih pogledov na preteklost, na položaj in na politični razvoj pri vseh južnoslovanskih narodih. Pri tem je Tumov najpomembnejši spis memoradum, ki ga je napisal kot poročevalec za Jugoslovansko socialdemokratsko stranko za obravnavo na pripravah za neuresničeni kongres socialističnih strank, načrtovan v Stockholmu, sredi leta 1917. To besedilo, napisano v nemščini, še ni bilo objavljeno.

Božidar Adžija. Tuma se med letoma 1928-1934 dopisoval pravzaprav z uredništvom revije Socijalna misao, katere urednik je bil skupaj z Gojkom Berberovićem pravnik dr. Božidar Adžija (1890-1941). Objavljenih je bilo 8 kopij pisem Tume uredništvu revije oziroma Adžiji, ${ }^{4}$ štiri Tumova pisma pa niso bila objavljena. V ZHT je ohranjenih 8 dopisov z lastnoročnim podpisom dr. Adžije in dva ciklostirani okrožnici uredništva revije. Dr. Adžija je Tumo 27. decembra 1928 prosil, da postane sodelavec revije. Tuma se je odzval in poslal v objavo povzetek predavanja z naslovom Delavec in priroda, o tem razmerju je predaval v Zagrebu v društvu Prijatelj prirode 19. decembra 1928. Tumov članek je izšel v februarski številki leta 1929 revije Socijalna misao. Dr. Adžija je kasneje (5. junija 1930) Tumo vabil, da sodeluje kot pisec manjših samostojnih publikacij, da se "najširim čitalačkim krugovima omogući upoznavanje važnih aktuelnih problema iz svih područja znanosti i umjetnosti.” ${ }_{5} \mathrm{~V}$ odgovoru na povabilo pa Tuma ni mogel zagotoviti, da bi lahko napisal ustrezno

1 Branko Marušič, "Dr. Henrik Tuma (1858-1935) in Istra”, v: Prispevki k primorski biografiki, Koper 2006, 123136 (poslej: Marušič, Prisperki).

2 Henrik Tuma, Pisma. Osebnosti in dogodki (1893-1935), Ljubljana-Trst 1994 (poslej: Tuma, Pisma).

3 Celotno ohranjeno Tumovo zapuščino hrani Raziskovalna postaja ZRC SAZU v Novi Gorici (poslej: ZHT).

4. Tuma, Pisma, 476-477.

5 Branko Marušič, "Zagrebška Socijalna misao (1928-1933) in Slovenci”, Čarnijev zbornik (1931-1996), Zbornik mednarodnih družboslovnih in humanističnih razprav, Ljubljana 1998, 271-276. 
besedilo. Za Socijalno misao je napisal nekrolog za enega vodilnih slovenskih socialistov Antona Kristana, ki je bil tudi sodelavec Adžijeve revije Socijalna misao.

August Arselin. Upokojeni direktor Osrednjega urada za zavarovanje delavcev v Zagrebu dr. Avgust Arselin je kot odvetniški kandidat v pisarni dr. Anteja Rosandića v Zagrebu priporočal (pismo 1. septembra 1931) Tumi, "da bi se pri eventuelnih sličajih svojih klijentov v Zagrebu poslužili pisarne g. dr. Rosandića.”

Vjekoslav Cvetišić. Hrvatski planinski pisec in predsednik planinskega društva "Sljeme” Vjekoslav Cvetišić (1881-1959) je imel s Tumo osebne in pismene stike tudi kot vodja tega društva. 25. novembra 1928 se je obrnil do Tume s prošnjo za oceno druge knjige iz serije njegovih štirih knjig $S$ planina i mora (1925-1934). Tuma mu je 22. decembra 1928 sporočil, da je oceno poslal v objavo dnevniku Jutro. ${ }^{6}$ Cvetišićevo knjigo je v oceni primerjal s pisanjem planinskega pisca dr. Juliusa Kugyja iz Trsta. Cvetišić je Tumi poslal tudi tretjo knjigo iz serije S planina i mora (pismo 30. junija 1930).

Marija Dekanić. Stanodajalka Tumovih otrok med počitnicami na otoku Krku (Punat). Ohranjena je kopija Tumovega dopisa, zadeva letovanje otrok. Dopis je nedatiran in tudi ni bil objavljen.

Drago Domjanić. Ohranjena je le kopija Tumovega dopisa z dne 9. februarja 1933. Pismo ni bilo objavljeno. Kot predstavnik Zveze umskih delavcev Slovenije je Tuma predsednika hrvaškega Pen kluba in člana banskega stola književnika dr. Domjanića (1875-1933) opozoril na potrebo društvenega organiziranja hrvaških intelektualcev. Tako posredovanje je Tumi nasvetoval dr. Ivo Politeo (pismo Tumi 6. februarja 1933). Domjanićev odgovor ni znan.

Ante Dukić. Učitelj na italijanskem oddelku deške vadnice v Gorici književnik Ante Dukić (1867-1952) je Tumo 11. avgusta 1907 prosil, da bi posredoval za zaposlitev njegovega prijatelja, bivšega trgovca z vinom na Reki. Tuma je Dukiću odgovoril. ${ }^{7}$

Ante Flego. V pismu, ki ga je Ante Flego poslal iz Voloskega Tumi, 13. avgusta 1922, se je zanimal za mnoga vprašanja iz najstarejše zgodovine

6 Objavljena z naslovom "Naše planine in gore” (Jutro, 30. 12. 1928, št. 304).

7 Tuma, Pisma, 79; Marušič, Prispevki, 126. 
Istre: “Čitam naime u 'Pravnom Vestniku'8 Vašu razpravu pak me silno vuče doznati od Vas nešto pobliže o svojoj užoj domovini, gde su u veći također Kajkavci, dakle Slovenci, sa vrlo starom jezikom." ${ }^{9}$ Tuma je Flegu obširno odgovoril (19. novembra 1922) in razložil svojo terorijo o avtohtonosti Slovanov v evropskem prostoru.

Milovan Gavazzi. Tuma se je v zadevi raziskovanja slovenske planinske terminologije obrnil s pismom (29. septembra 1928) do etnologa in takrat že profesorja zagrebške univerze Milovana Gavazzija (1895-1992). Tuma je želel izvedeti Gavazzijevo sodbo o slovenski/slovanski avtohtonistični teoriji. Ta mu je 17. novembra 1928 odgovoril, "da ne bih nikako prema svom dosadašnjim serioznim naučnim rezultatima mogao stati na stajalište, da je prakultura - u smislu prehistorijska kultura srednje Evrope, ali i dalje pače, rana historijska sve do nekoliko stoljeća poslije Kristusa, bila slavenska.” Tuma mu je ponovno pisal 19. novembra 1928.

Glas Slovenaca, Hrvata i Srba. Trije dopisi uprave zagrebškega lista (11. marca, 12. junija in 7. novembra 1918) zadevajo Tumovo naročniško razmerja $\mathrm{z}$ listom.

Branimir Gušić. Zdravnik in planinski pisec Branimir Gušić (1901-1975) je o problemih hrvaške planinske terminologije polemiziral leta 1932 v Hrvatskem planinaru z dr. Ivanom Krajačem. O problemu je napisal članek za Planinski vestnik. Objavo pa je literarni odsek Slovenskega planinskega društva zavrnil, kar je Tuma javil Gušiću 10. novembra 1932. Gušić je svoje nazore sporočil Tumi v pismu iz Zagreba 24. novembra 1932 in povedal med drugim, "da već od deset godina pišem u našim časopisima jezikom, što se bitno razlikuje od stila i pisanja naših planinarskih pisaca.” Tuma je v polemiko med Gušićem in Krajačem posegel z objavo članka. ${ }^{10}$ Gušić je sodeloval tudi v glasilu Slovenskih planincev Planinski vestnik.

Hrvatski planinar. Glasilu Hrvatskega planinarskega društva je Tuma pisal štirikrat, predvsem v zvezi z naročniškim razmerjem. Dva dopisa sta objavljena. ${ }^{11}$ Glasilo hrvaških planincev se je spomnilo Tumove sedemdesetletnice. ${ }^{12}$

8 Pravni vestnik je izhajal v Trstu. V Tumovih objavah je veliki poudarkov o avtohtonosti Slovencev/Slovanov.

9 Odlomek iz pisma objavljen v: Marušič, Prispevki, 135.

10 “Toponomastika i terminologija”, Hrvatski planinar, 29/1933, 133-139.

11 Tuma, Pisma, 161.

12 J. C. Oblak, "Dva jubileja (dr. Kugy - dr. Tuma)”, Hrvatski planinar, 24/1928, 186-189. 
Hrvatski turistički klub “Sljeme”. Obširna korespondenca med letoma 1926-1933 obsega 22 Tumovih dopisov in prav toliko dopisov društva. Stiki so nastajali in se ohranjevali predvsem s Tumovim predavateljskimi nastopi v Zagrebu in z njegovim raziskovalnim delovanjem (toponomastika). Večji del dopisov društva nosi tudi podpis predsednika Vjekoslava Cvetišića. Prav tako je del Tumovih dopisov, namenjenih društvu, naslovljenih na njegovega predsednika.

Hrvatsko planinarsko društvo. Tumovo dopisovanje je namenjeno predvsem njegovemu poslovnemu odnosu z društvom hrvaških planincev (članarina in naročnina) pa tudi raziskovalnim namenom (toponomastika). Ohranjeno je 18 kopij Tumovih dopisov in 17 dopisov društva.

Hrvatsko društvo planinara "Runolist”. Tuma se je v dopisu (30. aprila 1929) temu zagrebškemu društvu zanimal za zgodovino društva v povezavi s pisanjem knjige Pomen in razvoj alpinizma. Društvo mu je odgovorilo 17. avgusta 1929.

Istarska vinarska zadruga. Kot odgovor na Tumov dopis (22. februrja 1902) je zadruga iz Pulja 22. februarja 1902 sporočala ceno in vrsto terana, ki ga prodaja.

Vladimir Korać. Henrik Tuma je 12. septembra 1918 javil socialdemokratskemu politiku Koraću (1877-1941), da je pripravljen sodelovati v novi socialistični reviji Novo društvo. ${ }^{13}$ Korać je v odgovoru (12. septembra 1918) sprejel Tumovo ponudbo in mu sporočil, da bo revija v 4. številki objavila izvlečke njegovih člankov o Trstu iz dunajske revije Der Kampf..$^{14} \mathrm{~V}$ člankih je Tuma dokazoval slovanskost (Slovenci, Hrvati) severovzhodnih obal Jadranskega morja in njih pripadnost slovanskemu zaledju.

Kazimir Krušnjak. Bivši poročnik avstroogrske vojske je 9. januarja 1925 vpraševal Tumo, kje je njegov sin Jaroslav. Krušnjak je takrat živel v Ilirski Bistrici. Z Jaroslavom Tumo sta bila v italijanskem vojnem ujetništvu v kraju Ottaiano pri Neaplju. Tuma mu je 23. januarja 1925 odgovoril in sporočil, da njegov sin službuje v Pragi.

Rikard Katalinić Jeretov. Tuma se je pri Kataliniću (1869-1954), istrskemu književniku, zanimal (pismo ni ohranjeno), če so še na voljo zapisniki dalma-

13 Tuma, Pisma, 205.

14 Med objavljenimi Tumovimi članki je le eden posvečen Trstu. 
tinskega deželnega zbora. Katalinić mu je 7. marca 1908 odgovoril, ${ }^{15}$ da zapisnikov ni več na razpolago. Zraven pa še sporočal zadovoljstvo nad izidom volitev - zmaga hrvatsko-srbske koalicije - v banski Hrvatski.

Ivan Krajač. Odvetnik in politik Ivan Krajač (1877-1945) je v času dopisovanja s Tumo živel v Jastrebarskem. Prvo ohranjeno Tumovo pismo Krajaču je z dne 27. februarja 1930 ter spremlja pošiljko Tumovo knjige Imenoslovje Julijskih Alp. Nato je do začetka leta 1934 sledilo še 17 dopisov. Tumovi dopisi so namenjeni planinskim terminološkim problemom ter planinski organizaciji. Enako so naravnani tudi Krajačevi dopisi, vseh skupaj 18. V polemiki med dr. Gušićem in dr. Krajačem se je Tuma postavil na stran zadnjega. V ZHT sta ohranjena prepisa dveh daljših pisem Josipa Pasarića, urednika Hrvatskega planinara, dr. Branimiru Gušiću in predsedniku planinskega društva "Sljeme" Vjekoslavu Cvetišiću.

Matko Laginja. Hrvatski istrski politik Laginja (1852-1930) se je po ohranjenem sodeč, dvakrat oglasil Tumi. Prvič 16. septembra 1900 v povezavi z delovanjem slovenskih političnih strank v Avstrijskem primorju (tržaško politično društvo Edinost in goriška Narodnonapredna stranka) in drugič 13. novembra 1904, ko je poročal o obisku, ki ga je skupaj z Vjekoslavom Spinčićem in Matkom Mandićem opravil pri tržaškem namestniku. ${ }^{16}$ Morebitna Tumova pisma Laginji v ZHT niso ohranjena.

Matko Mandić. Istrski hrvatski politik Matko Mandić (1859-1915) je v pismu Tumi (6. januarja 1901) pozival Slovence na Goriškem naj podpirajo ob državnozborskih volitvah kandidaturo Matka Laginje. V pismu 22. januarja 1908, se je zahvalil za čestitko, ki mu jo je Tuma poslal ob 25-letnici javnega delovanja. ${ }^{17}$

Dragutin Mocnaj. Gozdar in književnik Mocnaj iz Zagreba se je pri Tumi (pismo 8. decembra 1930) zanimal za avtohtonistično teorijo o izvoru Slovencev. S tem v zvezi je poslal Tumi nekaj odlomkov svojega neobjavljenega romana. Tuma mu je zelo na kratko odgovoril (10. december 1930). ${ }^{18}$

Ante Pandaković. V neohranjenem pismu z dne 19. maja 1928 je Tuma vpraševal športnega organizatorja na Hrvaškem dr. Anteja Pandakovića

15 Pismo delno objavljeno v: Tuma, Pisma, 192-193 in v: Marušič, Prispevki, 130.

16 Tuma, Pisma, 239. Pismi sta deloma objavljeni v: Marušič, Prispevki, 127-128.

17 Tuma, Pisma, 260-261. Pismi sta deloma objavljeni v: Marušič, Prispevki, 129-130.

18 Tuma, Pisma, 278. 
(1891-1968), če se ukvarja s terminologijo in toponomastiko hrvaških gora. Pandaković mu je negativno odgovoril (1. julija 1928), "da se time nisam bavio ni sistematski ni stručno." 19

Ivo Politeo. Tumovo dopisovanje z odvetnikom Ivom Politeom (1887-1956) je bilo osredotočeno predvsem okoli delovanja društva Prijatelj prirode. Ta socialistična planinska organizacija je imela svoje podružnice v Sloveniji in na Hrvaškem. Izmed šestih (obdobje 1925-1933) so bili štirje Tumovi dopisi Politeu že objavljeni, ${ }^{20}$ Politeo je v času med letoma 1925-1933 poslal Tumi sedem dopisov in tri razglednice. Ohranjena je tudi kopija pritožbe, ki jo je predsednik centralnega odbora društva Prijatelj prirode v zvezi z razpustom društva poslal na bansko upravo Savske banovine (s. d., najverjetneje leta 1931). Tuma je imel s Politeom stike že iz časa pred prvo svetovno vojno, ko je ta sodeloval pri reviji Naši zapiski, ${ }^{11}$ ki jo je v Gorici urejal Tuma.

Pravda. Socialistični tednik Pravda je izhajal v Zagrebu med letoma 19171918. Tuma je 29. septembra 1918 poslal iz Trsta, kjer je zaradi vojne živel, na uredništvo lista (ni poznal naslova zagrebškega organizatorja) spomenico namenjeno sestanku (sklican za 6. oktober 1918) predstavnikov jugoslovanskih socialnodemokratskih strank v Zagrebu. V spremnem dopisu je listu tudi ponudil svoje sodelovanje. Spomenico, ohranjeno v Tumovi zapuščini, je objavil Dušan Kermavner. ${ }^{22}$

Prijatelj prirode. Društvo Prijatelj prirode je bilo, kot podružnica dunajske Die Naturfreunde, ustanovljeno leta 1905 v Sarajevu. Bilo je turistična in planinska organizacija, v njej so se zbirali predvsem delavci. V Sarajevu je deloval centralni odbor društva, ki je imelo sicer svoje podružnice v Makarski, Osijeku, Sarajevu, Slavonski Požegi, Subotici, Vršcu, Zagrebu (ustanovljena leta 1924) in Zenici. Na prelomu let 1930-1931 se je centralni odbor preselil iz Sarajeva v Zagreb. Oktobra leta 1931 je bila organizacija prepovedana, naslednje leto je obnovila svoje delovanje. Delokrog je poslej imela na območju celotne Jugoslavije, sedež centralnega odbora je bil v Sarajevu. Tuma, ki je sodeloval pri podružnicah društva Prijatelj prirode v Sloveniji, je imel pismene stike s centralnim odborom v Sarajevu in Zagrebu. Dopisoval pa

\footnotetext{
19 Prav tam, 321.

20 Prav tam, 342-345.

21 Ivo Politeo, "Nešto o socializmu u Hrvatskoj”, Naši zapiski, 11/1914, 119-124.

22 Zgodovinski arhiv Komunistične partïe Jugoslavïje, 5, Socialistično gibanje v Sloveniji 1869-1920, Beograd 1951, 365-366.
} 
si je tudi s zagrebško podružnico in sodeloval pri njenem delovanju tudi kot predavatelj. Objavljenih je bilo 20 Tumovih pisem centralnemu odboru ${ }^{23}$ in 16 Tumovih pisem zagrebški podružnici. ${ }^{24} \mathrm{~V}$ ZHT pa je ohranjeno še veliko neobjavljenega korespondenčnega in drugega gradiva, povezanega $\mathrm{z}$ delovanjem društva Prijatelj prirode v Zagrebu in Sarajevu.

Primorsko planinarsko društvo "Dinara". Tuma je v zvezi s pisanjem svoje knjige Pomen in razvoj alpinizma vpraševal splitsko planinsko društvo (pismo 10. decembra 1929) za nekaj podatkov o društveni zgodovini. Društvo mu je 19. decembra podatke poslalo, Tuma se je zahvalil 2. januarja 1930.

Petar Skok. Henrik Tuma je prvič navezal stik z jezikoslovcem Petrom Skokom (1881-1956) še preden se je iz Gorice po prvi svetovni vojni preselil v Ljubljano (1924). Tako povezavo mu je nasvetoval znani italijanski jezikoslovec Carlo Battisti, tedaj ravnatelj državne knjižnice v Gorici. Ohranjene so kopije petih Tumovih dopisov, prvi iz okoli leta 1924, štirje pa iz preloma let 1934-1935. V dopisih so Tumo zanimala jezikoslovna vprašanja (etimologija). Petar Skok mu je odgovoril na treh dopisnicah. Zanimala ga je Tumova ocena ${ }^{25}$ razprave o slovenski toponomastiki, ki jo je Skok napisal za slovensko revijo Etnolog: Skok je Tumi tudi nasvetoval, kje bi lahko objavil članek o slovenskih imenih od Devina do Čedada, k članku bi Skok napisal komentar.

Vjekoslav Spinčić. Tuma se je z istrskim hrvaškim politikom Vjekoslavom Spinčićem (1848-1933) povezoval v javnem življenju v letih pred prvo svetovno vojno. Arhiv Hrvatske v Zagrebu (RO Spinčić, kutije 87, 89 in 117) hrani dva Tumova izvirna dopisa iz leta 1901 in 1903 in dopis Tume leta 1924, ${ }^{26}$ naslovljena na Spinčića. V ZHT je kopija dopisa iz leta 1914 in izvirni Spinčićev dopis z dne 17. januarja 1925. V dopisu z dne 27. decembra 1924 piše Tuma Spinčiću iz Ljubljane: "Srečal sem v Beogradu g. Matka Laginja, s prav velikim veseljem, čilega in zdravega. Tembolj sem se spominjal na Vas izza časov, ko sta sporazumno delala in prebujala Istro. Žal, da sta danes pregnanca." Spinčić se je v odgovoru prav tako spominjal nekdanjega skupnega boja in dodal: "Dosegli smo ujedinjenje - žali bože nepodpuno! Odtegnulo nam pravo onaj teren, skoro sav, a i više, na kojom smo mi radili. I sad mjesto da se konsolidujemo, pak da s vremenom dobijemo ono što nam je ugrabljeno, mi se koljemo ko najbesniji psi ..."

\footnotetext{
23 Tuma, Pisma, 370-376.

24. Prav tam, 378-382.

25 Jutro, 21. 9. 1934, št. 217.

26 Tuma, Pisma, 479-480.
} 
Davida in Miroslav Sukalić. Mati in sin Sukalić s Sušaka sta se Tumi in njegovi družini zahvaljevala za sprejem ob Miroslavovem obisku Ljubljane, julija 1933.

$$
\text { * * * }
$$

Ta bežni pregled je opozorilo na zapuščino dr. Henrika Tume, ki je tudi vir za hrvaško politično zgodovino ter vir za zgodovino hrvaškega gorništva. Morda bo vzpodbudil k raziskavam, ki bodo prinesla nova spoznanja k slovensko-hrvaškim stikom v preteklosti.

\section{Povzetek}

Slovenski politik, publicist, domoznanski pisec, alpinist, odvetnik dr. Henrik Tuma (18581935) je v času svoje več kot polstoletne navzočnosti v javnem življenju navezal osebne in korespondenčne stike tudi z nekaterimi osebnostmi iz hrvaške javnosti pa tudi z nekaterimi hrvaškimi ustanovami in društvi. Ta prispevek našteva Tumove hrvaške dopisovalce in na kratko označi vsebino teh korespondenčnih stikov. Korespondenti so prikazani po abecednem redu. Vseh korespondentov (posamezniki, ustanove) je 30. Del Tumove korespondence je že bil objavljen (1994), Tumovo celotno zapuščino hrani Raziskovalna postaja ZRC SAZU v Novi Gorici. Tumovo korespondiranje je droben prispevek za zgodovino delavskega gibanja na Hrvatskem, pomembnejši je za zgodovino hrvaškega planinstva.

\section{Hrvatski korespondenti dr. Henrika Tume}

\section{Branko Marušič}

\section{Sažetak}

Slovenski političar, publicist, zavičajni pisac i alpinist, odvjetnik dr. Henrik Tuma (1858. 1935.) za svoje više od polustoljetne nazočnosti u javnome životu uspostavio je osobne i korespondentne doticaje s nekim osobama iz hrvatske javnosti, kao i s nekim hrvatskim ustanovama i društvima. Ovaj prilog navodi Tumine hrvatske dopisnike i ukratko prikazuje sadržaj tih korespondentnih kontakata. Korespondenti su prikazani abecednim redom, a ukupno ih je (pojedinaca i ustanova) 30. Dio je Tumine korespondencije već objavljen (1994.), a njegovu cjelovitu ostavštinu čuva Raziskovalna postaja ZRC SAZU u Novoj Gorici. Tumino dopisivanje je sitan prilog za povijest radničkoga gibanja u Hrvatskoj, a značajniji za povijest hrvatskoga planinarstva.

\section{I corrispondenti croati del dott. Henrik Tuma}

\section{Branko Marušič}

\section{Riassunto}

Il politico, pubblicista, scrittore regionale ed alpinista sloveno, l'avvocato dott. Henrik Tuma (1858-1935) durante la sua attività nella vita pubblica protrattasi per più di mezzo secolo, ha intrattenuto contatti personali e di corrispondenza con alcune persone della vita 
pubblica croata ma anche con certe istituzioni e società croate. Questo articolo nomina i corrispondenti croati di Tuma ed illustra brevemente il contenuto di tali contatti epistolari. I destinatari sono elencati in ordine alfabetico, per un numero complessivo di 30 tra singoli individui ed istituzioni. Una parte del carteggio di Tuma è già stata pubblicata (1994), mentre l'intero lascito è custodito presso la Raziskovalna postaja ZRC SAZU di Nova Gorica. Le lettere di Tuma rappresentano un contributo minimo per la storia dei movimenti operai in Croazia, ma la loro importanza è più considerevole per la storia dell'alpinismo croato.

\section{Croatian correspondents of Dr. Henrik Tuma}

\section{Branko Marušič}

\section{Summary}

Slovenian politician, publicist, local history author and alpinist, lawyer Dr. Henrik Tuma (1858-1935) made personal and professional correspondence contacts with some persons from Croatian public life, as well as some institutions and societies during his fifty year presence in the public life. This text cites some of Tuma's Croatian correspondents and covers in short the content of those correspondences. Correspondents are represented in alphabetical order and their total number (both individuals and institutions) is 30 . Part of Tuma's correspondence has already been published (1994) and his entire heritage is kept in Raziskovalna postaja ZRC SAZU in Nova Gorica. Tuma's correspondence is a small contribution to the history of worker's movement in Croatia and much more important to the history of Croatian mountaineering. 